\title{
Além da Técnica: Programa Musical Radiofônico Enquanto Aposta Linguística
}

\author{
Rafael Duarte Oliveira Venancio \\ Doutorando em Meios e Processos \\ Audiovisuais na Escola de Comunicações \\ e Artes da Universidade de São Paulo \\ (ECA-USP). É professor na área de \\ Cinema e Rádio no Centro Universitário \\ Senac, no Complexo Educacional FMU- \\ FIAM-FAAM e no Istituto Europeo de \\ Design de São Paulo.
}

Resumo: A cena acadêmica normalmente vê o rádio enquanto uma técnica, especialmente na questão dos programas musicais radiofônicos onde a prática midiática parece apenas servir à mera reprodutibilidade da música. No entanto, o rádio, mesmo com o surgimento de novos suportes, se mantém no escopo midiático. O presente artigo quer colocar uma nova visão no campo: o rádio enquanto linguagem. Usando o arcabouço teórico de Jacques Derrida e JeanFrançois Lyotard, com inspiração wittgensteiniana, veremos o rádio enquanto jogo de linguagem, impossibilitando sua morte meramente pela questão do suporte.

Palavras-chave: Linguagem midiática, Rádio, Música, Jogo de Linguagem

Abstract: The academic scene usually see the radio as a technique, especially in the matter of musical radio programs where the media practice appears to serve only the mere reproducibility of music. However, the radio, even with the emergence of new media, remains in scope. This article wants to put a new vision in the field: the radio as a language. Using the theoretical framework of Jacques Derrida and Jean-Francois Lyotard, inspired by Wittgenstein, we see the radio as a language game, which prevented his death merely by the support issue.

Keywords: Media language, Radio, Music, Language-game

\section{Introdução}

O programa musical radiofônico, normalmente, é caracterizado enquanto campo ampliador da técnica, da reprodutibilidade técnica, que leva o campo da Música a um novo patamar. Tal processo, considerado totalitário e prejudicial por pensadores como Theodor W. Adorno, normalmente ganha a pecha de "massificatório", deixando o meio de comunicação social, que é o rádio, enquanto mero operador de um processo mais amplo, que seria da Indústria Cultural.

Só que, enquanto técnica, o rádio pode estar fadado a sumir, ponto muito comum hoje no debate acadêmico sobre a prática midiática. Em tempos de Internet com o consumo sonoro sendo pautado pelos arquivos MP3 e pelo streaming de áudio, o rádio convencional se torna algo ultrapassado, digno apenas da história dos meios de comunicação. No entanto, não é bem isso que acontece se observarmos a cena midiática hoje em São Paulo com pessoas se encontrando com o rádio através dos diferentes suportes e meios de transmissão.

Assim, há a necessidade de um novo olhar sobre o rádio, um olhar dele enquanto linguagem. O presente trabalho aqui, seguindo a conceituação feita por Ludwig Wittgenstein na segunda fase de seu pensamento (marcado pelas Investigações 
${ }^{1}$ Tractatus é WITTGENSTEIN, 2009 e Investigações Filosóficas é WITTGENSTEIN, 1999. No entanto, para manter a normatividade dos estudos da área, utilizaremos a citação via proposições ou parágrafos. Ex: (TLP 5.6) e (IF, §528).

${ }^{2}$ Tal como bem pontuam Baker e Hacker (2005, p.62), o mais próximo que Wittgenstein dá de uma definição de jogo de linguagem está no parágrafo 7 das Investigações Filosóficas: “Na práxis do uso da linguagem (do §2), um parceiro enuncia as palavras, o outro age de acordo com elas; na lição de linguagem, porém, encontrar-se-á este processo: o que aprende denomina os objetos. Isto é, fala a palavra, quando o professor aponta para a pedra. - Sim, encontrar-se-á aqui o exercício ainda mais simples: o aluno repete a palavra que o professor pronuncia - ambos processos de linguagem semelhantes. Podemos também imaginar que todo o processo do uso das palavras [na linguagem] em §2 é um daqueles jogos por meio dos quais as crianças aprendem sua língua materna. Chamarei esses jogos de jogos de linguagem, e falei muitas vezes de uma linguagem primitiva como de um jogo de linguagem. E poder-se-iam chamar também de jogos de linguagem os processos de denominações das pedras e da repetição da palavra pronunciada. Pense os vários usos das palavras ao se brincar de roda. Chamarei também de 'jogos de linguagem' o conjunto da linguagem e das atividades com as quais está interligada" (IF, §7).

${ }^{3} \mathrm{O}$ trabalho sobre a lógica dialética é um sonho de Max Horkheimer desde o começo dos anos 1930. Sua ideia sempre foi realizá-lo em parceria. O primeiro parceiro seria Walter Benjamin, mas o caráter messiânico de suas ideias bem como o seu suicídio em 1940, fez o projeto ser cancelado. Depois, Horkheimer ficou na dúvida entre Herbert Marcuse e Theodor W. Adorno. Em um primeiro momento, Marcuse parecia ser o escolhido, mas a aproximação de Horkheimer a Adorno - graças ao manuscrito de Filosofia da Nova Música e das Teses da História, deixadas por Benjamin a Adorno como "herança", onde ambos concordaram completamente - logo mudaram os planos de colaboração e o trabalho da lógica dialética rumava para se tornar a Dialética do Esclarecimento.
Filosóficas ${ }^{1}$ ), o coloca enquanto um jogo de linguagem². Para revelar alguns mecanismos desse jogo, vamos utilizar como exemplo um gênero radiofônico: o programa musical.

Veremos, inspirados pelo arcabouço teórico de Jacques Derrida e Jean-François Lyotard, com filiação wittgensteiniana, como o programa musical radiofônico é uma aposta em uma contenda linguística que surge através do choque entre duas práticas (re)presentacionais consolidadas em nosso cenário simbólico.

Assim, tratado enquanto dimensão da linguagem, veremos como o rádio não pode ter sua morte decretada apenas pela questão do suporte. O rádio continuará existindo enquanto prática midiática sempre que alguém quiser disputar esse jogo. No entanto, antes de chegar a essa consideração, vamos ver como o rádio pode ser compreendido enquanto técnica dentro da dimensão da Indústria Cultural.

\section{Rádio e Música para Theodor W. Adorno}

A história da Indústria Cultural enquanto conceito de massificação e a da Dialética do Esclarecimento é o caso clássico de duas histórias autônomas que se transformam em uma só, já que a Dialética do Esclarecimento é o resultado do trabalho de quase 20 anos dedicados por Max Horkheimer ${ }^{3}$.

Quando ele pede e se decide pela ajuda de Adorno, Horkheimer divide com o colega as mesmas percepções analíticas. O encantamento de Horkheimer com os rascunhos da Filosofia da Nova Música fez com que a contribuição de Adorno no projeto da sua obra sobre lógica dialética incluísse também a cultura de massa sob a forma de um excurso.

A temática da Indústria Cultural era antiga nos escritos de Adorno. Podemos traçá-la desde dois artigos: Über Jazz e O Fetichismo na Música e a Regressão da Audição, de 1936 e 1938, respectivamente. Quase vinte anos mais tarde, Adorno (1981, p. 129) lembra que a tese desse artigo era afirmar que, enquanto música e produto comercial, "o objetivo do jazz é a reprodução mecânica do momento regressivo, da castração simbólica. 'Largue sua masculinidade, deixese ser castrado', o som eunuco de uma jazz band tanto zoa quanto proclama, 'e você será recompensado, aceito em uma fraternidade que divide o mistério da impotência com você".

Em miúdos, Adorno descreve que o jazz - tal como um tema da Indústria Cultural - massificaria seus apreciadores através da regressão da sua audição. Isso será compreendido no segundo artigo, que possui esse conceito no título, onde Adorno trata acerca do gosto musical. Na sua linha de raciocínio, na era das massas, o "próprio conceito de gosto está ultrapassado. A arte responsável orienta-se por critérios que se aproximam muito dos do conhecimento: o lógico e o ilógico, o verdadeiro e o falso. De resto, já não há campo para escolha; nem sequer se coloca mais o problema" (ADORNO, 1983, p. 165).

Assim, no gosto musical, ao invés do valor da própria coisa, o critério de julgamento é o fato de a canção de sucesso ser conhecida por todos. Essa postura massificadora da cultura musical só é reforçada por todos os âmbitos da Comunicação Social, pois, de acordo com o raciocínio de Theodor W. Adorno (1983, p. 165), o "comportamento valorativo tornou-se uma ficção para quem se vê cercado de mercadorias musicais padronizadas. Tal indivíduo já não consegue subtrair-se ao jugo da opinião pública, nem tampouco pode decidir com liberdade quanto ao que lhe é apresentado, uma vez que tudo o que se lhe oferece é tão semelhante ou idêntico".

Graças a esses artigos, de algum impacto no meio acadêmico, que Adorno foi chamado por Paul Lazarsfeld para integrar o seu Princeton Radio Research Project, 
garantindo a estadia dele nos Estados Unidos. No entanto, por motivos que nos dias atuais nos parecem óbvios, a parceria foi fadada ao fracasso principalmente devido à recusa de Adorno em aceitar a colaboração de produtores musicais radiofônicos, um fato que desagradou os patrocinadores da pesquisa.

Um dos estudos mais famosos de Adorno proveniente do Radio Project de Lazarsfeld é o Analytic Study of the NBC Music Appreciation Hour. Aqui a crítica versa sobre a educação musical de crianças feitas por um programa de rádio educativo que também servia de material didático nas escolas norte-americanas.

Adorno (1994, p. 353) identifica que "a tendência à pseudocultura musical se torna mais aparente no exato ponto onde o Music Appreciation Hour tenta, aparentemente, 'ativar' seus ouvintes: nos testes que são dados nas apostilas". Essas apostilas "empregam uma técnica mecânica que não é aplicada ao fenômeno auditivo concreto, mas apenas para a instrução dada pelo professor e, como um todo, feito para promover informação altamente questionável sobre música e não compreensão musical de fato" (ADORNO, 1994, p. 353).

Um exemplo disso pode ser visto na formulação dos testes do programa que "não se aplicam ao conhecimento de alguns fatos mencionados pelos comentadores, mas a julgamentos de valor promovidos por eles, virtualmente forçando as crianças a repetir julgamentos de valor e se adaptarem para darem normas ao invés de julgamentos autônomos" (ADORNO, 1994, p. 371).

Entre os exemplos coletados por Adorno (1994, p. 371-372), encontramos questões de múltipla escolha como essas: "Música acrescenta beleza e significado às palavras ao fazê-las (fáceis de pronunciar) (fortemente apelativas à nossa imaginação)" ou "Melodias Folk são (às vezes) (frequentemente) (invariavelmente) empregadas pelos compositores de música de câmara" ou mesmo "Por toda sua carreira, ele [Beethoven] experimentou (muita amargura e aflição) (constante felicidade)".

Junto com esses dados, Adorno (1994, p. 374-375) relaciona o ar cômico, de diversão [fun] do programa como sendo mais um fator da regressão da audição, indicando que a massificação por via cultural já é um processo iniciado mesmo nos âmbitos educativos. A linha de raciocínio aqui é extensa e descrita em uma nota de rodapé:

Uma análise do papel específico desempenhado pela noção de diversão na estética popular nos Estados Unidos e, no limite, também na Inglaterra, mostra que ela está ligada a noções como humor, brincadeira, relaxamento em resumo: descanso da chatice. Essa ideia pressupõe que arte não deve ser 'séria', nem mesmo séria dentro da esfera estética. Ele postula, adiante, que ela deve ser o alvo de um brincadeira, contrapondo a realidade exata da vida real e, finalmente, ela implica que o indivíduo não precisa fazer muito esforço e pode relaxar. Essas noções não são, de forma alguma, inerentes à arte ou, pelo menos, não completamente definem arte mesmo se alguma identifica o desenvolvimento de uma brincadeira nos seus elementos. A noção de diversão reflete um processo social que mecaniza e oprime o indivíduo de tal maneira em seu tempo livre que ele precisa ter alívio de suas responsabilidades. Na nossa época esse alívio assimila, sobre a forma de diversão, a forma de regressão à infância. $\mathrm{O}$ adulto que afirmar estar se divertindo é moldado no padrão do garoto risonho e despreocupado que certamente não existe como um ouvinte musical. Na nossa sociedade atual, com essa linha de demarcação entre trabalho e lazer, o indivíduo é oprimido não só quando está trabalhando, mas o efeito da opressão durante o processo de trabalho faz que ele o sinta em seu lazer também. Mesmo aqui, ele não pode ser um verdadeiro ser humano livre e consciente, mas deve regredir à infância do seu desenvolvimento individual para renovar sua capacidade produtiva adulta. Esse efeito mutilador da sociedade contemporânea sobre as esferas da vida parecem, na superfície, ser retirado 
do processo capitalizante, destaque para o fato de que a noção de diversão se torna sacrossanta especialmente nos países mais industrializados. Uma teoria completamente desenvolvida da regressão da audição será necessária para analisar todas as implicações da diversão enquanto norma estética (ADORNO, 1994, p. 374-375).

No Radio Project, Adorno também discutiu as ideias benjaminianas de $A$ Obra de Arte na Era de sua Reprodutibilidade Técnica com o artigo "The Radio Symphony". "Adorno defendia a tese de que a sinfonia retransmitida no rádio dava apenas uma imagem da execução real, como o filme de uma peça teatral dava apenas uma imagem da representação real; portanto, a pretensão da indústria radiofônica de trazer a verdadeira música às massas era fundamentalmente discutível", trazendo apenas a impotência e inconsciência, ao efeito de neutralização (WIGGERSHAUS, 2006, p. 271).

A essas ideias preliminares, o contexto de fuga do nazismo e incertezas perante o futuro renovavam o que seria o conceito de Indústria Cultural consolidado na Dialética do Esclarecimento. As ideias da Dialética do Esclarecimento, apesar de serem compatíveis à ideia de barbárie do progresso defendidas por Walter Benjamin, eram muito críticas em relação às ideias benjaminianas de massa, utilizando os mesmos exemplos para acirrar mais ainda o debate.

Benjamin (1994, p. 190) citava diretamente os filmes da Disney como um dos representantes da "tecnização [que] abriu a possibilidade de uma imunização contra tais psicoses de massa". Já na Dialética do Esclarecimento, vemos que "os filmes de animação fazem mais do que habituar os sentidos ao novo ritmo, eles inculcam em todas as cabeças a antiga verdade de que a condição de vida nesta sociedade é o desgaste contínuo, o esmagamento de toda resistência individual" (ADORNO \& HORKHEIMER, 1985, p. 130).

Ao invés de falarem de Mickey, Adorno e Horkheimer (1985, p. 130) citam outro amigo de slapstick comedy: "Assim como o Pato Donald nos cartoons, assim também os desgraçados na vida real recebem a sua sova para que os espectadores possam se acostumar com a que eles próprios recebem".

Vemos assim que na magnus opus de Adorno e Horkheimer eles se voltam para Kracauer em suas afirmações mais duras sobre o processo da razão instrumental - a razão movida a fins eclodida pelo processo do esclarecimento, Aufklärung tal como indica Thomas Y. Levin (apud KRACAUER, 1995, p. 19).

Nas palavras de Theodor Adorno (2007, p. 98), anos depois da Dialética do Esclarecimento, "nos nossos rascunhos nós falamos de 'cultura de massa'. Nós substituímos essa expressão por 'indústria cultural' para excluir do escopo a interpretação acordada pelos seus defensores: que é algo tal como uma cultura que surge espontaneamente das massas, uma forma contemporânea de arte popular".

Adorno afirma que, na verdade, a Indústria Cultural não é do domínio do popular, mas sim das possibilidades das capacidades contemporâneas técnicas assim como a concentração administrativa e econômica. Na Indústria Cultural, muito mais do que a cultura virar uma mercadoria, a mercadoria vira cultura e nem uma nem outra são necessariamente vendidas ou compradas.

Um exemplo disso é clássico na Dialética do Esclarecimento: “Chesterfield é apenas o cigarro da nação, mas o rádio é o porta-voz dela. Ao integrar todos os produtos culturais na esfera das mercadorias, o rádio renuncia totalmente vender como mercadorias seus próprios produtos culturais" (ADORNO \& HORKHEIMER, 1985, p. 149). As consequências são terríveis pois, "nos Estados Unidos, ele [o rádio] não cobra nenhuma taxa do público. Deste modo, ele assume a forma de 
uma autoridade desinteressada, acima dos partidos, que é como que talhada sob medida para o fascismo. O rádio torna-se aí a voz universal do Führer" (ADORNO \& HORKHEIMER, 1985, p. 149).

Dentro do conceito de Indústria Cultural, a Dialética do Esclarecimento vê que "o que se poderia chamar de valor de uso na recepção dos bens culturais é substituído pelo valor de troca; ao invés do prazer, o que se busca é assistir e estar informado, o que se quer é conquistar prestígio e não se tornar um conhecedor. O consumidor torna-se a ideologia da indústria da diversão, de cujas instituições não conseguem escapar" (ADORNO \& HORKHEIMER, 1985, p. 148).

Dessa forma, "é preciso ver Mrs. Miniver, do mesmo modo que é preciso assinar as revistas Life e Time. Tudo é percebido do ponto de vista da possibilidade de servir para outra coisa, por mais vaga que seja a percepção dessa coisa. Tudo só tem valor na medida em que se pode trocá-lo, não na medida em que é algo em si mesmo" (ADORNO \& HORKHEIMER, 1985, p. 148).

Assim, além da regressão da audição, a Indústria Cultural promove o fetiche, pois "o valor de uso da arte, seu ser, é considerado como um fetiche, e o fetiche, a avaliação social que é erroneamente entendida como hierarquia das obras de arte - torna-se seu único valor de uso, a única qualidade que elas desfrutam" (ADORNO \& HORKHEIMER, 1985, p. 148). Assim o programa musical radiofônico - e o Rádio como um todo - se tornam mero fetiche da técnica

\section{A importância de uma visão própria para a Comunicação Social}

É quase impossível que qualquer trabalho que busque analisar os meios de comunicação social via sua teoria não pague tributo às ideias de Theodor W. Adorno e Max Horkheimer e aos estudos dos meios de comunicação de massa efetuados por Adorno. Só que vale a pena vermos de onde Adorno fala e o quão próximo ou distante está do presente trabalho, calcado no campo das Ciências da Comunicação.

Ora, mas nunca devemos esquecer que Adorno fala do ponto de vista da Sociologia e da Filosofia Social, e não das Ciências da Comunicação. Assim, não há pretensão alguma, em Adorno, de considerar detalhes que só são possíveis considerar quando levamos em conta os domínios da Comunicação, da Linguagem e da Produção de Sentido.

Não estamos aqui negando o legado de Adorno e muito menos o de Marx, Lukács e demais marxistas. A proposta do presente trabalho não é a mesma que aquela praticada por Jacques Derrida: a Desconstrução. Aqui, no nosso caso, é a desconstrução das práticas midiáticas e sua pedra-chave, que é a linguagem.

Isso, de certa forma, não é explicitado em termos sociológicos apenas. Falar em reificação ou em integração, não nos levaria a esse caminho que coloca a comunicação em primeiro lugar antes, por exemplo, da sociedade. Claro que dessa forma podemos encontrar algo que poderia ser chamado de uma paralogia.

Ora, eis a virtude de uma paralogia, entendida também - principalmente por Lyotard (1984) - enquanto um movimento contra as formas já consolidadas de análise e reflexão. Dessa forma, "paralogia deve ser distinguida da inovação: a última está sob o comando do sistema, ou pelo menos usado para melhorar sua eficiência; a primeira é um movimento (cuja importância não é normalmente reconhecida até mais tarde) jogado na pragmática do conhecimento" (LYOTARD, 1984, p. 61).

Assim, a tarefa de se pesquisar em Comunicação Social deve sempre representar uma vontade. Uma vontade por mais paralogias comunicacionais. 
A metacomunicação só é possível quando aceitarmos as contradições dos seus jogos de linguagem. E o mais importante: ver as práticas midiáticas pautadas por jogos de linguagem.

\section{Rádio enquanto prática midiática com jogos de linguagem}

O que seria ver o rádio enquanto uma prática midiática submetida a determinados jogos de linguagem? Ora, a produção de materiais para veiculação no rádio possuiu sempre uma principal fronteira em relação aos demais materiais artísticos que usam a voz. Claro que o rádio sempre pode ser o lugar para músicas, declamação de poesias e, até mesmo, transmissão de peças de teatro, no entanto, se tornou cada vez mais necessário realizar materiais próprios para o rádio se pensarmos em uma Retórica do Rádio.

Esses materiais próprios podem ser divididos em três grupos: (1) técnicos, composto por vinhetas, chamadas de programas e de prefixos; (2) orações, composto por gêneros radiofônicos que possuem sua raiz nas atividades orais (i.e. retóricas) encontradas na vida social. Um exemplo claro disso são os discursos e as mesas redondas que remontam às Assembleias políticas; e (3) textuais, composto por gêneros radiofônicos que possuem sua raiz nas atividades escritas encontradas na vida social. Esse gênero, principalmente em um primeiro momento, é caracterizado pelas notícias que são compostas tal como se fosse uma leitura de um jornal impresso.

No entanto, em tese, todos esses materiais podem ser preparados anteriormente, seja na forma de um texto para ser lido ou, até mesmo, gravado e apenas transmitido quando for o momento apropriado. Só que a constituição das produções midiáticas do rádio não tomou esse caminho à primeira vista óbvio.

Seja devido ao alto custo de realizar essas tarefas técnicas (gravação e redação), seja graças à fusão de duas características midiáticas no rádio com forte apelo atual na cena digital - o mediatismo com o imediatismo, formando algo que é considerado a interatividade típica do rádio que, em um neologismo, poderia

${ }^{4}$ A questão do (i)mediatismo pode ser facilmente identificada na forma que o rádio é ensinada atualmente, especialmente no âmbito brasileiro. A ponte teórica construída entre o diálogo (símbolo maior do mediatismo) e o caráter de um "agora" (imediatismo) permeia os manuais de área e, até mesmo, pesquisas científicas sobre o assunto. Como exemplo disso, podemos citar Ortriwano (1998) e Silva (2007). ser chamado de (i)mediatismo ${ }^{4}$-, essas situações levaram o rádio a se constituir de uma maneira que é realizada (ou passa a impressão de que é realizada) "ao vivo", unindo as pessoas à voz/fala (seja ela do profissional de rádio, da fonte, ou mesmo do fato) no momento de sua emissão.

Sabemos que essa dimensão da voz na fala radiofônica possui um quê de Retórica graças à sua dimensão de elocutio. A ideia de uma elocutio que pode ser concebida previamente, tal como um hábito para o orador, foi muito bem usada, na análise estética da literatura feita pela Escola de Crítica de Yale. Esse grupo, que tem Jacques Derrida e Paul de Man como seus principais nomes, instaura a Retórica no campo filosófico da Estética, formando o último bastião da Paraestética para Carroll (1987), que liga Derrida e de Man a Nietzsche, passando por Foucault e Lyotard.

Ora, olhar a questão da dimensão da fala no rádio com o solo proporcionado por Jacques Derrida se mostra frutífero. Isso se deve à noção de escritura. Para entendê-la precisamos primeiramente dissociar escritura de escrita. Para Derrida (2008, p. 11), escrita engloba "não apenas os gestos físicos da inscrição literal, pictográfica ou ideográfica, mas também a totalidade do que a possibilita; e a seguir, além da face significante, até mesmo a face significada", abrangendo tudo que possui inscrição e que não pertença à ordem da voz.

No entanto, a escrita - em uma tradição filosófica que, normalmente, recorre ao Fedro, de Platão - é depreciada enquanto uma situação de detrimento da riqueza e vivacidade da fala. Essa questão voz-escrita é o melhor exemplo do trabalho filosófico da Desconstrução para Derrida: há um par de oposição A e B, em que o 
A é mais importante do que o B. Só que na linha de argumentação de Derrida há sempre a demonstração de que $A$ possui uma mesma base do que $B$, já que ambos derivam de um conceito $\mathrm{B}^{\prime}$, mais abrangente e à primeira vista mais parecido com B.

Agora, a leitura de Gramatologia passa a nos indicar um caminho diferente na história da linguagem: não é mais fala-escrita ( $A-B)$, mas sim escritura-falaescrit(ur)a ( $\left.B^{\prime}-A-B\right)$, onde há primazia do $B^{\prime}$, mas não uma indissociação dele ao B. Dessa forma, não devemos ver apenas a escritura como articulação, mas como suplementariedade.

Sendo a suplementariedade um processo indefinido, a escritura é, dessa forma, o "suplemento por excelência, pois ela marca o ponto onde o suplemento se dá como suplemento de suplemento, signo de signo, tendo o lugar de uma fala já significante: ela desloca o lugar próprio da frase, a vez única da frase pronunciada hic et nunc por um sujeito insubstituível, e retrorretira o nervo da voz. Ela marca o lugar da reduplicação inicial" (DERRIDA, 2008, p. 343).

É essa abertura que constitui o problema abordado pelo presente trabalho, resumido pelo enunciado "como podemos observar essa escritura na fala radiofônica". Dessa forma, é necessário analisar, tendo em vista o arcabouço teórico derridariano, o B' da fala radiofônica e sua manifestação na construção dessa prática midiática. Com isso, devemos considerar os sintomas da manifestação dessa escritura enquanto parerga (plural de parergon), conceito clássico da Estética presente na Crítica do Juízo, de Kant, e retomado por Jacques Derrida.

Ora, o conceito de parergon ganha destaque na Estética com a Crítica do Juízo. Kant (2005, p. 45) constata que os ornamentos (parerga), tal como as molduras de uma pintura, apesar de não fazerem parte da representação artística e, até mesmo, prejudicarem o belo genuíno, são essenciais para uma ampliação e um reconhecimento do gosto estético.

Essa consideração de Kant - que poderia, até mesmo, passar despercebida - é retomada por Jacques Derrida em seus estudos de Estética. Neles, Derrida indica que o parergon de uma obra de arte indica uma necessidade, uma falta, que essa possui em seu processo representacional. O que constitui os parerga, no raciocínio de Derrida (1987, p. 59-60) "não é apenas a sua exterioridade enquanto um acréscimo, mas sim a ligação interna estrutural que os fixam na falta interior da obra (ergon). E essa falta é constitutiva da própria unidade do ergon. Sem essa falta, o ergon não precisaria de parergon. A falta do ergon é a falta de um paregon".

Dessa forma, esses ornamentos - tal como a moldura para uma pintura ou uma coluna para um busto - é o que fazem a obra de arte ser reconhecida enquanto tal. É a última fronteira entre o que é e o que não é. Dessa forma, pensando no amplo escopo teórico de Derrida, vemos o quanto o parergon está relacionado com a escritura e com o projeto de desconstrução de antagonismos binários.

Derrida também acredita em um trabalho, ao menos especulativo, em cima do parergon. Especulativo porque podemos vê-lo, conceituá-lo, no entanto, ele é indissociável do ergon. Isso é exemplificado por Derrida (1981) através de um texto de Mallarmé intitulado Mimique onde a própria imitação do nada é imitação, mesmo se caracterizarmos que para haver imitação é necessário imitar algo.

Essa referência sem referente é o puro trabalho na moldura, a possibilidade aberta pelo parergon que traz para a arte a mesma possibilidade que a archiescritura para a linguagem. "Em um espaço constantemente diferido há uma escritura que funda a fala e a escrita. Fala e escrita, então, supõe uma archi- 
${ }^{5}$ New Wittgenstein é uma corrente de interpretação com marco inaugural na publicação de livro de mesmo nome em 2000, organizado por Rupert Read e Alice Crary. Entre os principais filósofos atuais que estão relacionados sobre essa alcunha estão Stanley Cavell e John McDowell.

\footnotetext{
${ }^{6}$ Apesar de estarmos citando pontualmente o primeiro volume (Understanding and Meaning) do projeto de comentário analítico das Investigações Filosóficas, feito por G. P. Baker e P. M. S. Hacker, é interessante saber que tal afirmação é consistente em toda a obra, especialmente no terceiro volume, intitulado Meaning and Mind, movendo tanto sua exegeses quanto seus ensaios. $O$ que há em Undestanding and Meaning é uma espécie de consideração total da IF, intitulada por eles como overview da estrutura e argumento do livro de Wittgenstein.
}

escritura como condição de possibilidade de toda a linguagem" (FERRO, 1992, p. 102). Se a archi-escritura é a possibilidade de toda a linguagem, o parergon é a possibilidade de toda a arte.

Por ser a possibilidade de toda a arte, é no parergon que reside a construção de uma legitimidade do rádio enquanto mídia. Podemos ir até além, pensando na ideia benjaminiana de que os meios de comunicação de massa surgem através da reprodutibilidade técnica das obras de arte, dizendo que é o parergon que define as regras do rádio ser rádio, ou seja, como o rádio pode ser recortado dos demais sons do mundo.

Entramos, assim, na questão daquilo que podemos chamar de (re)presentação. Ora, a proposição 5.6 do Tractatus Logico-Philosophicus é uma das mais conhecidas frases do livro de Ludwig Wittgenstein: "Os limites da minha linguagem significa os limites do meu mundo" (TLP 5.6). De função essencial dentro da chamada Teoria Pictória do Primeiro Wittgenstein, essa frase também animou diversos estudos dentro do campo das Ciências da Linguagem.

À ela, normalmente, se adiciona uma outra proposição do Tractatus, a 4.015: "A possibilidade de todas as símiles, de todas as imagens [imagery] de nossa linguagem, reside na lógica da representação". Para muitos, inclusive para a linha de interpretação "formada" no século XXI denominada New Wittgenstein", essas duas proposições mostram a conexão entre as obras das duas fases wittgensteinianas: a do Tractatus e a das Investigações Filosóficas.

No entanto, o foco pretendido por esse trabalho não é entrar no debate acerca do caráter terapêutico que Wittgenstein pode ou não pode ter. Tal como ficou claro pelas duas proposições wittgensteinianas selecionadas, o foco aqui é a questão da representação dentro de um domínio da linguagem.

E aqui somos tributários das Investigações Filosóficas que, tal como bem diz Gomes (2001), coloca a questão da representação do mundo - de certa forma, dentro da totalidade proposta por TLP 4.015 e 5.6 - enquanto apresentação do mundo. Há aqui uma questão que vincula essas duas palavras por causa de sua diferença prefixal: "Representação constitui esse ato substitutivo, incluso no 're', que nos remete a uma rememoração enquanto apresentação nos fala do mundo colocado pelo ato de significá-lo" (GOMES, 2001, p. 36).

Isso é uma referência a uma importante passagem das Investigações Filosóficas:

Em lugar de "representabilidade" pode-se aqui dizer também: apresentabilidade (Darstellbarkeit) num meio determinado de apresentação. E partindo de tal apresentação, um caminho mais seguro pode contudo levar a um emprego mais amplo. Por outro lado, uma imagem pode se impor a nós e não servir para nada (IF, §397).

Para melhor compreender esse jogo de apresentar-representar no mundo, vale a pena retomar o escopo do $\$ 397$ dentro dessa obra de Wittgenstein. Baker e Hacker $(2005)^{6}$, por exemplo, consideram esse parágrafo enquanto fronteira entre duas seções de pensamento descritas no livro. É uma conclusão dos estudos de Wittgenstein acerca da imaginação e um gatilho para o início da seção de sua investigação acerca do Vorstellungwelt, o mundo das representações.

Devemos, então, citar o parágrafo para qual o §397 prepara o terreno reflexivo.

"Mas quando me represento algo, ou também quando vejo realmente objetos, então tenho algo que meu próximo não tem." - Compreendo-o. Você quer 
olhar em torno de si e dizer: "Apenas eu tenho ISSO." - Para que essas palavras? Não servem para nada. - Sim, não se pode dizer também que "não se trata aqui de um 'ver' - e, portanto, também de um 'ter' - de um sujeito, e também de um eu"? Não poderia perguntar: aquilo de que você fala, e diz que apenas você o tem, - em que medida você o tem? Você o possui? Você nem sequer o vê. Sim, você não deveria dizer que ninguém o tem? É também claro: quando você exclui logicamente que um outro tem algo, também perde o sentido dizer que você o tem.

Mas, então, do que é que você fala? Na verdade, disse que sei, no meu íntimo, o que você tem em mente (meinst). Mas isto significaria: eu sei como se tem em mente conceber e ver esse objeto, como se tem em mente, por assim dizer, designá-lo por meio do olhar e de gestos. Sei, neste caso, de que modo olhase em frente e em torno de si - e outras coisas. Creio que se pode dizer: você fala (quando você, por exemplo, está sentado no quarto) de um 'quarto visual'. Aquilo que não tem possuidor é o 'quarto visual'. Não posso possuí-lo assim como não posso andar nele, olhá-lo ou mostrá-lo. Não me pertence, na medida em que não pertence a nenhum outro. Ou: não me pertence, na medida em que empregaria para ele a mesma forma de expressão que emprego para o quarto material, no qual estou sentado. A descrição do último não precisa mencionar nenhum possuidor, não precisa mesmo ter nenhum possuidor. Mas, então, o quarto visual pode não ter nenhum. "Pois não tem outro senhor senão ele e nenhum nele" - poder-se-ia dizer.

Imagine uma figura de paisagem, uma paisagem de fantasia, com uma casa - e que alguém perguntasse: "A quem pertence a casa?" - A resposta poderia ser: "Ao camponês que está sentado no banco em frente dela". Mas este não pode, por exemplo, entrar em sua casa (IF, §398).

Postos aqui o $\$ 397$ e o §398, é necessário descrever os dois movimentos explicitados por eles nas Investigações Filosóficas. O primeiro parágrafo, o da (re) presentação, demonstra uma questão interessante neste ponto do pensamento de Wittgenstein.

§§316-62 e a investigação subsequente da imaginação em §§363-97 podem dar a impressão enganadora de abandono das investigações acerca da linguagem e significado linguístico para favorecer temas da filosofia da mente. Mas Wittgenstein teve que incluir um exame de tais conceitos psicológicos tais como pensar e imaginar (bem como entender e significar algo). Quando ele escreveu o Tractatus, ele tomou concepções particulares de pensar, significar e entender, consideradas garantidas e negligenciou a análise delas. Ele pensou que isso era o assunto próprio da psicologia, não da filosofia. Isso tinha sido um erro porque aquilo que ele assumiu enquanto pertencente à psicologia era, na verdade, metapsicológico e demandava elucidação filosófica enquanto parte da empreitada de clarificar a natureza da representação linguística. Mas concepções acerca do pensar, imaginar e imaginação distorceram reflexões acerca da natureza da linguagem desde a alvorada da filosofia até os dias atuais (BAKER \& HACKER, 2005, p. 17).

É o momento no qual Wittgenstein deixa clara a natureza da linguagem enquanto (re)presentação. Isso é da ordem do gramático, da lógica dos jogos de linguagem aos quais somos submetidos. É errôneo achar que, por exemplo, a imaginação delimita as fronteiras do sentido, podendo até expandi-lo. Na realidade, a imaginabilidade está entre os critérios lógicos já postos. Tal "gramática não é um 'grande espelho'. Ela não reflete a essência das coisas. Ao contrário, ela é autônoma. Ela determina a essência das coisas" (BAKER \& HACKER, 2005, p. 19).

Mas não podemos acreditar, tal como bem nos coloca o $\S 398$, que essa gramática é apenas mais uma forma de Vorstellungwelt:

$\S \S 398-427$ lida muito brevemente com grandes temas: o 'mundo subjetivo' da experiência do sentido e da imaginação, do "eu" e da auto-referência, 
os conceitos de consciência e auto-consciência. A discussão antecedente da imaginação levou ao pensamento de uma particularidade do "mundo de representações" (Vorstellungwelt) - a propriedade inalienável do 'quarto visual' da experiência subjetiva. Mas essa ilusão idealista está enraizada em uma má interpretação das formas gramáticas. O papel do pronome de primeira pessoa não é para se referir a um sujeito (deixando-o sozinho para uma substância mental ou 'dono da experiência'), mas sim é um índice de um utterance [enunciado, ato de fala] (BAKER \& HACKER, 2005, p. 18).

${ }^{7}$ Por causa de sua estrutura, trataremos Le Différend (LYOTARD, 2007) em citações tal como as obras de Wittgenstein. Ex: (LD, §188).
O que há de importante para se notar aqui é que estamos postos na linguagem imersos em seus jogos e que tudo, na verdade, é (re)presentação não só por sua falta de autonomia, mas porque tudo são utterances da lógica do mundo. Não somos donos do quarto visual, nem do Vorstellungwelt, somos parte dele.

Assim, só resta a nós e a todos outros enunciados do mundo entrarem nessa lógica da linguagem que é determinada por seus jogos. Eis aqui que o pensamento de Jean-François Lyotard nos dá bastante subsídio. Subsídio para sabermos como agimos no mundo, como os jogos de linguagem operam e como os jogamos.

Para Lyotard, em sua obra Le Differénd ${ }^{7}$, os atores de uma prática artística e/ou midiática (ou qualquer outra atividade (re)presentacional) não fazem as regras dos jogos, apenas podem atuar nelas. E tal atuação é jogando sob a forma de apostas, tal como em um jogo de cartas onde jogar e apostar estão interconectados.

"Quando Cézanne usa seu pincel, o que está em aposta na pintura é posto em questão; quando Schönberg senta em seu piano, é o que está em aposta na música; quando Joyce pega sua caneta, é o que está em aposta na literatura" (LD, §192). Dessa forma, mesmo os movimentos mais radicais nos campos artísticos são estratégias de jogar dentro deles. Não há criação, apenas disputa sem consenso.

Dessa forma, Lyotard, ao mesmo tempo, nega as conclusões de Habermas e de Luhmann, "rascunhando o desenho de uma política que respeita tanto o desejo de justiça e o desejo pelo desconhecido" através da compreensão de jogos de linguagem que são jogos de não-zero soma (LYOTARD, 1984, p. 67).

Com isso, Lyotard desenha algo que é mais bem referenciado em Le Differénd: a questão da política enquanto um saber com metarregras. Podemos classificá-lo como um saber mais de base, um saber-práxis que é vital nas formas de ação da linguagem. Como Lyotard não o denomina em seus livros - até porque ele não se limita à política, mas também a qualquer situação de saber com função-práxis -, denominaremos ele aqui enquanto saber performativo.

O saber performativo é o campo dos diferendos, dessas phrases (enunciados, logos) em disputa, e das estratégias de como jogar os jogos de linguagem. É uma aposta e/ou uma estratégia como jogar tais jogos, caracterizando-o assim enquanto um saber de base. Neste ponto,

você não brinca com a linguagem. E nesse sentido não há jogos de linguagem. Há apostas amarradas a gêneros do discurso. Quando essas apostas são alcançadas, nós falamos em sucesso. Há conflito, então. O conflito, no entanto, não é entre humanos ou entre qualquer entidade; na verdade, ele resulta de enunciados [phrases]. (...). Não importa qual é regime, todo enunciado é, em princípio, o que está apostado em um diferendo entre gêneros do discurso (LD, $\S 188)$.

Isso que possibilita Lyotard dizer que "tudo é político se a política é a possibilidade do diferendo na ocasião de menor relação. Política não é tudo, apesar de que ela acredita que é um gênero que contêm todos os gêneros. Não é um gênero" (LD, 
$\S 192)$. Assim, ele é performativo no sentido de conseguir instaurar o agonismo. E é isso que temos que ter em mente ao pensar na questão das práticas midiáticas.

\section{Jogando o jogo de linguagem do Rádio: Programa musical enquanto aposta}

Assim, aqui podemos abarcar a proposta que definimos já no título do presente trabalho: o programa musical enquanto aposta, uma maneira de jogar o jogo que constitui o rádio enquanto prática midiática. Aliás, devemos enfatizar que é uma espécie de aposta apenas.

Se pensarmos na cena radiofônica paulistana, podemos identificar cinco apostas claras, cada uma representando o que poderíamos chamar, usando o arcabouço lyotardiano, enquanto gêneros do discurso. São eles: musical, jornalístico, esportivo, humorístico e de variedades. Outro gênero do discurso possível na cena radiofônica paulistana, mas ausente atualmente, é o ficcional. A radionovela, que teve papel fundante na consolidação do rádio, é o principal exemplo desse último.

Assim, o programa musical é apenas uma das possibilidades de "jogar" o rádio. Diferentemente dos demais gêneros do discurso, o programa musical lida com a (re)presentação de duas práticas autônomas: o rádio e a música. Dos tipos de programas citados, apenas o jornalístico possui alguma semelhança nesta questão, especialmente quando pensamos em existenciais que perpassam todos os jornalismos (de rádio, TV, mídia impressa, mídia digital).

Ao invés de considerarmos, tal como Adorno, o rádio enquanto mais um meio técnico para a música, temos que ver que há uma demanda mútua nesse tipo de aposta envolvida: temos que tanto reconhecer esse programa enquanto veículo de enunciados radiofônicos como de enunciados musicais.

É por isso que podemos ver, especialmente durante a história do programa radiofônico musical no Brasil, especialmente nos grandes centros, o quanto o enunciado radiofônico foi influenciado pelo enunciado musical. Essa condição é vista cotidianamente: basta ligar o rádio em alguns desses programas que vemos o quanto que a voz do locutor é pautada pelo gênero musical no qual o programa é focado.

Se um programa de rádio toca música eletrônica (techno, trance), temos um locutor cuja velocidade de prosódia se assemelha ao ritmo acelerado da batida das músicas do gênero. Na era dourada do rádio brasileiro, com as Cantoras do Rádio e os programas musicais da Rádio Nacional, temos locutores-apresentadores com voz impostada e melódica, tal como o ritmo musical da época.

Aliás, esse tipo de aposta pode ser vista analogamente sempre quando há a intesecção de duas atividades (re)presentacionais, miméticas. Um exemplo fora do rádio está no início do cinema sonoro, grande propulsor da indústria fonográfica, em pioneiros tal como Walt Disney.

Seus desenhos animados sonoros constituem exemplo clássico de como podemos ver um puro trabalho na moldura de uma arte está na (re)presentação dela em outra arte, com manutenção dos dois parerga. Um dos pioneiros do som no desenho animado, Walt Disney, nos anos 1930, acreditava nas possibilidades de sincronização entre som e imagem. Trabalhando primeiro a banda sonora, para depois realizar a animação, Disney utilizava o tempo musical (com ajuda do metrônomo) para pautar o tempo de animação.

Tal diretriz possibilitou a construção de desenhos animados musicais que trabalhariam "conceitualmente" a música, projeto iniciado com a série Silly Symphony, passando pelos curtas do Mickey (destaque para The Band Concert, 
1935, onde há overlapping de dois tempos musicais e de animação), chegando ao projeto de Fantasia (1940).

Só que, mesmo com esse trabalho conceitual, o desenho animado jamais seria a música apresentada na banda sonora. Assim, tal como o mímico de Mimique, vemos em cena o próprio parergon da música através de situações como a personagem Soundtrack em Fantasia, o balanço de árvores imitando o metrônomo ou a definição de humores tal como é feito com Donald em The Band Concert.

Como dissemos anteriormente, há em cena um constante jogo linguístico entre suplementariedade e escritura, cujo objetivo do presente trabalho não é só identificá-lo, mas também analisá-lo para ver tanto esse processo de falta ergônica visto por Derrida no parergon (e visto aqui nas representações paregônicas de uma linguagem por outra linguagem) como para entender a fundante afirmação de Hegel de que a Estética não é uma calística, um jogo de belos, mas sim de percepções e sensações.

O rádio não escapa disso e o programa musical radiofônico é sempre uma aposta nesse jogo posto pelo rádio, mas com respeito às gramáticas da música (no caso, a música gravada pela indústria fonográfica em seus primórdios de seu tratamento enquanto produto). A questão aqui não é de técnica, tal como acredita a vertente adorniana, mas sim de uma economimesis, tal como nos indica Jacques Derrida.

Assim,

por causa de sua universalidade qualitativa, o juízo [judgment of taste] parece com o julgamento lógico que, sem dúvida, nunca é só rigor. O não-conceitual parece o conceitual. Uma semelhança muito estranha, uma proximidade ou afinidade [Ähnlichkeit] singular que, em algum lugar (a ser especificado depois ["Economimesis"] traça a mimesis enquanto uma interpretação do belo que firmemente rejeita a imitação. Não há contradição aqui que não é reapropriada pela economia da physis enquanto mimesis (DERRIDA, 1987, p. 76).

Por isso que não há uma única forma de apostar na natureza da linguagem enquanto (re)presentação do mundo. As práticas midiáticas - no caso, seu imaginário, não seu corte, o simbólico, que compõe o paregon - podem combinar diversos parerga, dando possibilidade de surgir produções tal como o radiofônico musical.

Isso é uma aposta em um jogo de linguagem. Por isso, inclusive, não podemos, com advento com os meios digitais de transmissão e suporte, decretar uma morte do rádio. Mesmo em podcasts, rádios digitais e Internet, a prática, o jogo, se mantém, possibilitando vermos novos programas radiofônicos musicais sendo elaborados e postos entre os sons do mundo.

\section{Considerações Finais}

Essa condição decreta uma total independência da prática radiofônica daquilo que chamamos rádio, o aparelho. A eterna confusão entre suporte e prática midiática está com os dias contados com a Internet. O rádio, a TV e o jornal não estão fadados a sumir porque o que irá desaparecer gradativamente é o aparelho de rádio, o televisor e o papel-jornal, mas não o dispositivo de produção que faz o rádio ser um som distinguível dos demais sons, que faz a TV ser uma imagem sonora diferente das demais e o jornal ser reconhecido entre milhares de palavras escritas.

Ora, não é isso que está aí neste começo de segunda década do século XXI? Ainda não há uma demanda por rádio que leva as pessoas quererem receptores FM ou apps de emissoras de rádio em seus celulares? Não há a possibilidade de escutar 
rádios via streaming em seus sites oficiais e em repositórios que concentram quase uma cena global do rádio?

O rádio em si não é um suporte, nem é um programa de computador que pode ficar obsoleto. $O$ rádio é uma linguagem e tal prática existirá mesmo quando for criada a verdadeira caixa-preta midiática, sonho da cibernética e cada vez mais próximo com smartphones e tablets.

Assim, o que está em risco é aquilo que é vendido por lojas de eletrodomésticos e não aquilo que sai de uma emissora, pequena ou grande, oficial ou pirata, com inúmeros funcionários ou apenas um apaixonado diante de um notebook. Tal situação nos permite interpretar melhor as palavras de R. Murray Schafer:

Qual foi a origem do rádio? Que ela não é recente, isto é certo. O rádio existiu muito antes de ter sido inventado. Ele existia sempre que havia vozes invisíveis: no vento, no trovão, no sonho. Ao ouvir a história em retrospecto, verificamos que ele era o sistema de comunicação original através do qual os deuses falavam com a humanidade. Era o recurso utilizado pelas vozes que, livres do mundo dos fenômenos, comunicavam seus pensamentos e desejos aos atemorizados mortais (...). O rádio continuou a ser um veículo imponente, mesmo depois de sua sacralização. Lendas contam como os antigos reis da Mesopotâmia e da China podiam transmitir mensagens lacradas em caixas aos governadores de províncias distantes, que ao abri-las ouviam os comandos do rei. Ter uma "audiência" com o rei implicava em não ousar olhar seu rosto. "Audiência" vem do verbo latino audire, ouvir. A mesma raiz fornece a palavra "obedecer" (obaudire), que significa ouvir de baixo. Ouvir é obedecer. Essa é a primeira coisa a ser lembrada ao se falar de rádio. Ele é um veículo temível, porque não se pode ver quem ou o quê produz o som: um excitamento invisível para os nervos. (SCHAFER, 2008, p. 237).

O rádio sempre existirá. Sempre existirá desde que um enunciado sonoro entrar em contenda com um enunciado auditivo seguindo determinadas regras. É o jogo de linguagem, base de qualquer prática midiática e possibilidade de sua manutenção.

\section{Referências bibliográficas}

ADORNO, T. W. "Perennial Fashion - Jazz". In: Prisms. Cambridge: MIT Press, 1981.

ADORNO, T. W. "O Fetichismo da Música e a Regressão da Audição". In: ARANTES, P. E. (org). Os Pensadores: Benjamin, Horkheimer, Adorno, Habermas. S. P.: Abril Cultural, 1983.

ADORNO, T. W. "Analytical Study of NBC Music Appreciation Hour". The Musical Quarterly. vol. 78, no 2. Oxford: OUP, summer/1994.

ADORNO, T. W. The Culture Industry. London: Routledge, 2007.

ADORNO, T. W. Filosofia da Nova Música. São Paulo: Perspectiva, 2009.

ADORNO, T. W. \& HORKHEIMER, M. Temas Básicos da Sociologia. S. P.: Cultrix, 1978.

ADORNO, T. W. \& HORKHEIMER, M. Dialética do Esclarecimento. R. J.: J. Zahar, 1985.

AUSTIN, J. L. How to do Things with Words. Cambridge: HUP, 1975. 
BAKER, G. P \& HACKER, P. M. S. Wittgenstein: Understanding and Meaning (Vol. 1 of An Analytical Commentary on the Philosophical Investigations - Part II: Exegesis $\S \S 1-184)$. Segunda edição (revisada por P. M. S. Hacker). Malden: Blackwell, 2005.

BENJAMIN, W. "A Obra de Arte na Época de sua Reprodutibilidade Técnica". In: Obras Escolhidas v.1 - Magia e Técnica, Arte e Política. São Paulo: Brasiliense, 1994.

CARROLL, D. Paraesthetics: Foucault, Lyotard, Derrida. New York: Methuen, 1987.

DERRIDA, J. Dissemination. Chicago: University of Chicago Press, 1981.

DERRIDA, J. The Truth in Painting. Chicago: University of Chicago Press, 1987.

DERRIDA, J. Limited Inc. Campinas: Papirus, 1991.

DERRIDA, J. Gramatologia. São Paulo: Perspectiva, 2008.

FERRO, R. Estrutura y Desconstrucción. Buenos Aires: Biblos, 1992.

GOMES, M. R. Repetição e Diferença nas Reflexões sobre Comunicação. São Paulo: Annablume, 2001.

HEGEL, G. W. F. Estética. Lisboa: Guimarães Editores, 1993.

KANT, I. Critique of Judgment. Mineola: Dover, 2005.

KRACAUER, S. The Mass Ornament. Cambridge: HUP, 1995.

LYOTARD, J-F. The Postmodern Condition. Minneapolis: UMP, 1984.

LYOTARD, J-F. The Differend. Minneapolis: UMP, 2007.

ORTRIWANO, G. S. "Rádio: interatividade entre rosas e espinhos". Revista Novos Olhares. Ano I, no 2, São Paulo: ECA/USP, 2ํsemestre/1998.

SCHAFER, R. M. "Rádio Radical e a Nova Paisagem Sonora". In: MEDITSCH, E \& ZUCULOTO, V. (org). Teorias do Rádio (volume II). Florianópolis: Insular, 2008.

SILVA, J. L. O. A. Rádio: oralidade mediatizada. São Paulo: Annablume, 2007.

UNESCO. “Creative Industries". Unesco.org. Paris: UNESCO, 2009.

WIGGERSHAUS, R. A Escola de Frankfurt. Rio de Janeiro: DIFEL, 2006.

WITTGENSTEIN, L. Investigações Filosóficas. São Paulo: Nova Cultural, 1999.

WITTGENSTEIN, L. Tractatus Logico-Philosophicus. In: Major Works. N. Y.: Harper, 2009. 